\section{The effect of short term rest after handling stress on electrocardiogram indices in goat}

\author{
Amir Saeed Samimi, Javad Tajik, \\ Somayeh Bakhshaei, Adel Mirjordavi \\ Department of Clinical Sciences, School \\ of Veterinary Medicine, Shahid Bahonar \\ University of Kerman, Iran
}

\section{Abstract}

This study examined the effects of short term rest after handling stress on electrocardiographic parameters, and evaluated the probable effects of age and sex on them. It was performed on 40 clinically healthy pure Raini goats. The animals were divided into four groups consisting of 10 male kids (up to one year old, $15-20 \mathrm{~kg}$ body weight), 10 female kids (up to one year old, 15-20 kg body weight), 10 female adult goats (1-5 years old, $25-35 \mathrm{~kg}$ body weight) and 10 male adult goats (1-3 years old, 20-40 kg body weight). Five minutes after transporting animals to a standing stock, the electrocardiograms were obtained from each goat. Our results showed that the proportion of sinus tachycardia in stress was significantly $(\mathrm{P}<0.05)$ higher than other cardiac arrhythmia in this study. It seems that the insignificant change in heart rate as a result of short term rest was due to insufficient time to reduce the effects of handling stress, and it was concluded that cardiac arrhythmias observed in the clinically healthy Cashmere goats in stress periods could be accepted as the physiological arrhythmias, so no treatment is necessary.

\section{Introduction}

Skilled diagnosis of heart disease in livestock has improved in recent decades. 1,2 Electrocardiography (ECG) is a non-invasive diagnostic method for diagnosis of disturbances in the genesis and spread of the cardiac impulses. ${ }^{3}$ ECG records and heart auscultation have been introduced as accurate and very useful tools for evaluation and comparison of cardiac function, diagnosis of cardiac arrhythmias and cardiac murmur in small ruminants. ${ }^{3,4}$

Goats, economically important producers of meat, hair and milk, have a high economic value in many countries. ${ }^{5}$ Although the impor- tance of obtaining normal values of ECG for specific breeds of animals besides the high variability in the ECG parameters in goats has been emphasized, 3,6 little studies have been done the effects of short term rest after handling stress on ECG parameters in healthy goats. Additionally, there is no previous study exploring the effects of age and sex on changes of ECG parameters during short term rest after handling stress in ruminants.

The Raini goat, one of the most famous breeds in Iran, is raised in large numbers in the Kerman province of Iran where goat production contributes significantly to the agricultural economy.7 There is little information regarding Raini goat and to the best of our knowledge, there is no previous study regarding the effects of handling stress on ECG parameter in this valuable breed. This study was undertaken to evaluate the effects of short term rest after handling stress on ECG parameters, and to evaluate the probable effects of age and sex on them in this breed.

\section{Materials and Methods}

This study was performed in July 2013 on 40 clinically healthy pure Raini goats, selected randomly from research farm of the Agriculture School of Shahid Bahonar University of Kerman, central Iran. The animals were divided into four groups consisting of 10 male kids (up to one year old, $15-20 \mathrm{~kg}$ body weight), 10 female kids (up to one year old, 15-20 kg body weight), 10 female adult goats (1- 5 years old, $25-35 \mathrm{~kg}$ body weight) and 10 male adult goats (1-3 years old, $20-40 \mathrm{~kg}$ body weight).

The animals were reared under the same husbandry conditions in the same group pen. Five minutes after transportation of animals to a standing stock (rest time), the electrocardiograms were obtained from each goat on a bipolar base apex lead using a single channel ECG machine (Cardiomax FX-2111, Fukuda, Japan) with a paper speed of $25 \mathrm{~mm} / \mathrm{s}$ and calibration of $10 \mathrm{~mm}$ equal to $1 \mathrm{mV}$. The ECG was recorded when the animals were thought to be in a quiet standing position using an alligator-type electrode attached to the skin. The positive electrode of lead I (left arm) was attached to the skin of the fifth intercostal space just caudal to the olecranon and the negative electrode (right arm) on the jugular furrow about the lower $1 / 3$ of the left side of the neck and the earth was attached away from these two electrodes.1,2 Alligator clips were fixed to the skin after application of methyl alcohol.

A magnifying glass was used for analyzing and measuring ECG parameters. Using this method of measurement, the precision of duration and amplitude was $0.02 \mathrm{~s}$. and 0.05
Correspondence: Amir Saeed Samimi, Department of Clinical Sciences, School of Veterinary Medicine, Shahid Bahonar University of Kerman, 7616914111 Kerman, Iran.

Tel.: +98.341.3202935 - Fax: +98.341.3222047.

E-mail: amirsamimi90@yahoo.com

Key words: Electrocardiograms; short term rest handling stress; raini goat

Contributions: the authors contributed equally.

Conflict of interest: the authors declare no potential conflict of interest.

Received for publication: 16 April 2015.

Revision received: 10 June 2015

Accepted for publication: 17 June 2015.

This work is licensed under a Creative Commons Attribution NonCommercial 3.0 License (CC BYNC 3.0).

(C) Copyright A.S. Samimi et al., 2015

Licensee PAGEPress srl, Italy

Veterinary Science Development 2015; 5:5954

doi:10.4081/vsd.2015.5954

$\mathrm{mV}$, respectively. The heart rate was calculated by measuring the average six R-R intervals of each trace. To describe the QRS complex, the first negative deflection was designated as $Q$, the first positive wave was named $R$ and the negative deflection after $R$ was designated $S$. If the QRS complex was a single negative deflection, it was described as the QS pattern.1,2,8 In the case of biphasic $\mathrm{P}$ or T waves $(-/+$ or $+/-)$, the amplitudes of two phases were summed.

\section{Statistical analysis}

Statistical analysis was performed using SPSS12 (Chicago, IL, USA). Comparisons of heart rate, waves' amplitude and duration, and P-R, Q-T and R-R intervals were performed using paired-samples t tests, while Chi-square test was used for comparison of QRS wave conformation, and Fisher exact tests were used for comparison of $\mathrm{P}$ and T waves' conformation. Differences were considered significant at $\mathrm{P}<0.05$.

\section{Results}

The results of the measurement of the heart rate, besides amplitude, duration and configuration of ECG waves before and after short term rest in different genders and age groups of Raini goats are shown in Figure 1 and in Supplementary Tables S1 and S2.

The heart rates before and after rest was $108 \pm 4.7$ and $108.3 \pm 4.6$ beats/min, respective- 
ly. There was no significant difference between the two periods in heart rates, and amplitude, duration and configuration of ECG waves, except for Q-T interval, which showed a marginally significant difference $(\mathrm{P}=0.09)$.

The average age of female goats was significantly higher than male goats (mean \pm mean standard error: $2.39 \pm 0.38$ and $1.44 \pm 0.15$ years, respectively). Each sex was also evaluated separately. In male goats, the duration of $\mathrm{P}$ wave increased significantly $(\mathrm{P}=0.041)$ and so did the duration of $\mathrm{R}-\mathrm{R}$ interval $(\mathrm{P}=0.036)$. In female goats, R-R interval significantly increased $(\mathrm{P}=0.046)$ and the heart rate showed a marginally significant decrease in second evaluation $(\mathrm{P}=0.08)$.

The goats were divided into two groups according to their maturity: kids (animals up to 1 year old) and adults (animals higher than 1 year old). Before rest, the heart rates of kids were significantly higher than adults $(\mathrm{P}<0.01)$, while the difference was not statistically significant after rest. Each group was evaluated separately. In kids group, Q-T interval had a marginally significant difference between the two periods $(\mathrm{P}=0.065)$, while in the other group, none of the measured parameters showed significant difference between the two periods.

The goats were divided into three groups according to their age, as: $\mathrm{G}_{1}<1$ year, 1 year's $\leq \mathrm{G}_{2}<3$ years and, $\mathrm{G}_{3} \geq 3$ years. Before rest, the heart rate of $G_{1}$ was significantly higher than the other two groups $(\mathrm{P}<0.01)$ and heart rate showed significant difference between the two periods in the three groups $(\mathrm{P}<0.01)$.

\section{Discussion and Conclusions}

Electrocardiography and auscultation, as non-invasive diagnostic methods, have been introduced as the preferred method for evaluation of electrical and mechanical activity of heart and diagnosis of cardiac dysrhythmia and cardiac murmur.1,2 Base apex lead has been proposed as the best and standard lead for monitoring cardiac arrhythmias in large animal medicine and is used routinely. 1,2 There are a few previous studies regarding the normal ECG parameters in healthy goats and to the best of our knowledge, there is no previous study exploring the effect of handling stress on ECG parameters in small ruminant. 5

According to our results, the mean heart rate in Raini goats was 108 beats/min which was within the reported normal range of goats by Smith (70-110 beats/min for adult goats and 120-160 beats/min for kids) ${ }^{9}$ and was higher than the reported normal range by Radostits et al. (70-90 beats/min for goat). 10 Sinus tachycardia denotes an increase in heart rate that is initiated by the sinoatrial node. The term

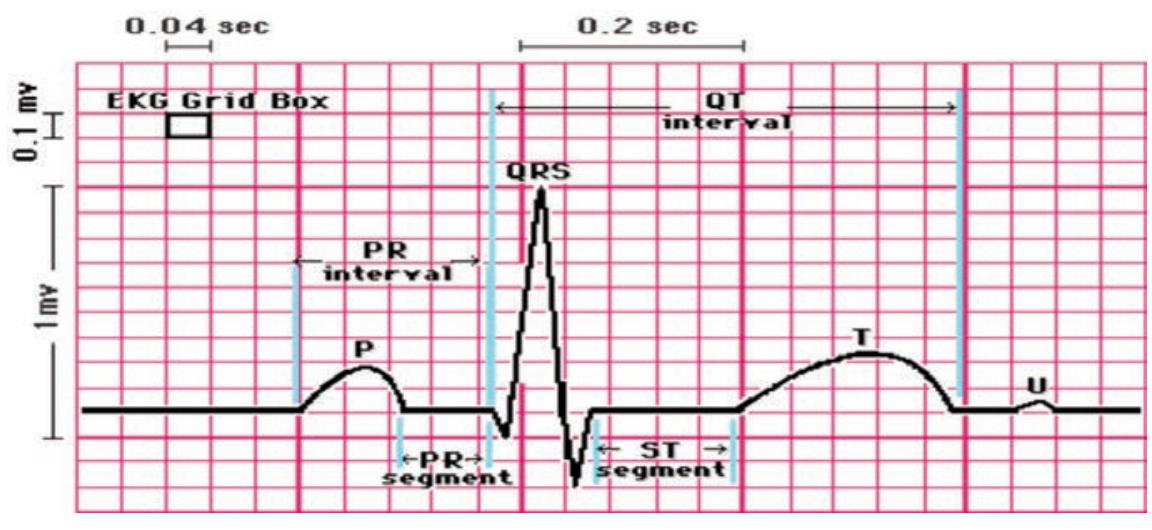

Figure 1. Electrocardiogram profile (comprising: waves amplitude and duration, and duration of P-R, Q-T and R-R intervals) in base apex lead system (paper speed $25 \mathrm{~mm} / \mathrm{s}$, sensitivity $10 \mathrm{~mm} / \mathrm{mv}$ ).

sinus tachycardia is caused by detectable influences such as pain, excitement, stress, pregnancy, exercise, hyperthermia, decrease in arterial blood pressure and administration of adrenergic drugs. 10 The heart rate returns to normal when the influence is removed or relieved. Stress has been proposed as an important reason for tachycardia and our results showed that the proportion of the sinus tachycardia in stress was significantly $(\mathrm{P}<0.05)$ higher in this study.11,12 It is well known that stress increases in plasma corticoid concentrations, 13,14 which are regulated by the corticotrophin-releasing factor (CRF) that is secreted by the hypothalamus in response to stress. ${ }^{15}$ Corticotrophin-releasing factor acts at additional sites in the central nervous system to stimulate sympathetic noradrenergic outflow to the heart rate and inhibit cardiac parasympathetic nervous activity, resulting in increased heart rate.16-18 It seems that the insignificant change in heart rate due to short term rest was due to insufficient time to reduce the effects of handling stress. Because there were no clinical signs of cardiac problems (edema, jugular distension or pulsation) in evaluated animals, this cardiac rhythm irregularity could be categorized as physiologic arrhythmias. ${ }^{19}$

A heart rate higher than 120 and 90 in goats up to 1 year old and higher than 1 year old, respectively, has been considered as sinus tachycardia. 10 In the current study, $31.6 \%$ of Raini goats in kid animals (up to one year old) and $64 \%$ of adult animals (over 1 year old) had a heart rate higher than 120 and 90 , respectively, and could be considered as sinus tachycardia ( $47.2 \%$ of all examined animals). It may be suggested that the higher heart rate of kids might be due to stress and excitation caused by isolation of kids from their dams. Sinus tachycardia has been reported as the most common cardiac arrhythmia in newborn
Iranian fat-tailed lambs. ${ }^{20}$ We found no clinical sign of heart problem or cardiac insufficiency in any of the animals with cardiac arrhythmia. Pourjafar et al. suggested occurrence of sinus tachycardia, sinus arrhythmia and sinoatrial heart problem in goats as the physiologic cardiac arrhythmias. ${ }^{20}$

No significant change in ECG parameters (configuration, amplitude and duration of ECG waves) was observed, except Q-T interval, in the current study. It seems that short term rest in our study was not sufficient to remove the effect of handling stress on ECG parameters. Although we found no specific cause for Q-T interval change, it seems that the short term rest was sufficient to affect ventricular depolarization-repolarization interval.

Sinus arrhythmia was the other common arrhythmia seen in this study. The observation of ECGs revealed that the sinus arrhythmia was associated with stress which is similar to the result of Pourjafar et al., ${ }^{19}$ Rezakhani and Khajedehi studies. ${ }^{21}$ The animals in stress period showed this arrhythmia more frequently. ${ }^{22}$ Sinus arrhythmia is a normal physiologic arrhythmia that occurs at slow resting heart rates and is associated with variation in the heart rate. This arrhythmia has been detected in anorectic cattle, ${ }^{23,24}$ clinically healthy Najdi goats and late pregnant sheep, 19,20 but has not been reported in piglets during handling stress. 12 None of the animals with sinus arrhythmia in this study had obvious clinically systemic disease, pregnancy or anorexia. Low vagal tone (high sympathetic tone) could be suggested as the cause of this arrhythmia in these animals. ${ }^{1,2}$ Furthermore, stress is a time of hemodynamic, hormonal, and catecholamine fluctuations, which may provoke cardiac arrhythmias. 25

Sheep and goat ECG parameters in stress are of interest to researchers and there are a block without appearance of clinical signs of 
few previous studies exploring this issue. ${ }^{21}$ Although hearing cardiac dysrythmia is possible in horses and cattle with low heart beat, in small ruminant with high heartbeat, due to small size of heart, the heart sounds have little value in diagnosis of heart arrhythmia. ${ }^{26}$

It was concluded that the cardiac arrhythmias observed in the clinically healthy Raini goats in stress periods could be accepted as the physiological arrhythmias, so no treatment is necessary. Furthermore, the results of the present study showed that the physiological cardiac arrhythmias in Raini goats might be increased coincidentally with stress and showed little effect of sex and age on ECG parameters in base-apex lead in Raini goats during stress period. Additionally, sufficient time to rest should be considered before taking ECG to remove the effects of handling stress.

\section{References}

1. Rezakhani A, Papahn AA, Shekarfroush S. Analysis of base apex lead electrocardiograms of normal dairy cows. Veterinarski Arhiv 2004;74:351-8.

2. Rezakhani A, Papahn AA, Gheisari HR. Cardiac dysrhythmias in clinically healthy heifers and cows. Rev Med 2004;15:159-62.

3. Escudero A, Gonzalez JR, Benedito JL, et al. Electrocardigraphic parameters in the clinically healthy Zamorano-leones donkey. Res Vet Sci 2009;87:458-61.

4. Cebra C, Cebra M. Diseases of the cardiovascular system. In: Sheep and goat medicine. Philadelphia: Saunders Elsevier; 2002.

5. Tajik J, Samimi AS, Tajik T, et al. Electrocardiographic parameters in clinically healthy Cashmere goats. Online J Vet Res 2013;17:528-34.
6. Mohan NH, Niyogi D, Singh HN. Analysis of normal electrocardiograms of Jamunapari goats. J Vet Sci 2005;6:295-8.

7. Mozaffari AA, Shahriarzadeh MH, Ja'fari KG. Analysis of serum and cerebrospinal fluid in clinically normal adult Iranian Cashmere (Raini) goats. Comp Clin Pathol 2011;20:85-8.

8. Deroth L. Electrocardiographic parameters in normal lactating Holstein cow. Canad Vet J 1980:21:271-7.

9. Smith BP. Large animal internal medicine. St. Louis: Mosby; 2009.

10. Radostits OM, Gay CC, Hinchcliff KW, Constable PD. Veterinary Medicine: A Textbook of the Diseases of Cattle, Horses, Sheep, Pigs and Goats: Saunders Elsevier Philadelphia, PA; 2007.

11. Bernal 0, Concepcion M. Cardiac arrhythmias in women. Rev Esp Cardiol 2006;59:6 09-18.

12. Ville KG, Bertels S, Geers R, et al. Electrocardiogram parameters of piglets during housing, handling and transport. Cambridge J 1993;56:211-6.

13. Wagnerw C, Oxenreider SL. Adrenal function in the cow. Diurnal changes and the effects of lactation and neurohypophysial hormones. J Anim Sci 1972;34:630-5.

14. Meinlschmidt G, Martin C, Neumann I, Heinrichs M. Maternal cortisol in late pregnancy and hypothalamic-pituitaryadrenal reactivity to psycosocial stress post partum in women. Stress 2010;13:163-71.

15. Smith RF, Donson KG. Hormonal interactions within the hypothalamus and pituitary with respect to stress and reproduction in sheep. Domest Anim Endocrinol 2002;23:75-85.

16. Fisher LA. Corticotropin-releasing factor: endocrine and autonomic integration of responses to stress. Trends Pharmacol Sci 1989;10:189-93.
17. Machida N, Nakamura T, Kiryu K, Kagota K. Electrocardiographic features and incidence of atrial fibrillation in apparently healthy dairy cows. Zentralbl Veterinarmed A 1993;40:233-9.

18. Davis KL, Charney D, Coyle JT, Nemeroff C. Corticotropin-releasing factor. In: neuropsycho-pharmacology: the fifth generation of progress. An official publication of the American College of Neuropsychopharmacology. Philadelphia: Lippincott Williams \& Wilkins; 2002.

19. Pourjafar M, Badiei K, Chalmeh AA, et al. Comparsion of cardiac arrhythmias between late pregnancy and early post-partum periods in clinically healthy Iranian fat-tailed sheep. Pakistan Vet J 2011;31: 309-12.

20. Pourjafar M, Badiei K, Chalmeh AA, et al. Age-related cardiac arrhythmias in clinically healthy Iranian Najdi goats. Bulg J Vet Med 2012;15:37-43.

21. Rezakhani A, Khajedehi GR. Normal electrocardiographic parameters of the goat. Pajouhesh va Sazandegi 2001;14:102-3.

22. Rezakhani A, Ejtehadi M. Some electrocardiographic parameters of the fat tailed sheep. Zentralbl Veterinarmed A 1980;27: 1552-66.

23. Machida N, Okamato KG, Minami S, et al. Cardiac arrhythmias in normal Holstein heifers. J Jpne Vet Med Assoc 1991;44: 1176-9.

24. Gentile A, Guglielmini C, Cipone M. Alterazioni del ritmo cardiaco nel bovino in rapporto col digiuno. Arch Vet Ital 1992; 44:100-7.

25. Murphy J, Slodzinsk M. Right ventricular outflow tract tachycardia in the parturient. Int J Obstet Anesth 2008;17;275-8.

26. Rezakhani A, Godarzi M, Mokhber-dezfuli MR, Zarifi M. Prevalence of S3 and S4 in horse. J Vet Res 2009;5:35-9. 